\title{
BURDEN OF MALARIA IN SINDH, PAKISTAN: A TWO YEARS SURVEILLANCE REPORT
}

\author{
M. Akbar Nizamani, Nawaz A. Kalar and Imdad A. Khushk
}

\begin{abstract}
OBJECTIVES: To determine the malaria burden in Sindh province of Pakistan and suggest appropriate measures to prevent and control this problem.

DESIGN: A descriptive study.

SETTING: All districts of Sindh during January 2004 to December 2005.

METHODS: This study was based on data of provincial malaria control program of Sindh. Active and passive case detection and malariometric survey of population of Sindh are done by health workers of this program in all districts. A monthly report is then sent to the central pool at Hyderabad for compiling and analysis of the data.

RESULTS: In years 2004 and 2005, all districts of Sindh were covered by malaria control program. Malaria microscopists observed more than $\mathbf{2 . 8 2}$ million blood slides by all three methods of case collection with an average blood examination ratio of 4 . More than 68,000 slides were reported positive for malarial parasite with an average slide positivity rate of $2.41 \%$. Average plasmodium falciparum ratio in years 2004 and 2005 was $33 \%$ and $37.2 \%$ respectively. Estimated annual parasite incidence was 5.6 per 1000 population and 3.85 per 1000 population in years 2004 and 2005 respectively. In this period, malaria remained endemic in whole of Sindh throughout the year but incidence was relatively higher in coastal areas and rainy and post rainy seasons.

CONCLUSION: Malaria is endemic in whole Sindh province round the year. It becomes high risk in coastal districts in rainy and post rainy seasons. Annual parasite incidence is unacceptably high and plasmodium falciparum ratio is increasing in many districts of Sindh. Hence, effective malaria control under global initiative of Roll Back Malaria Program is the need of hour in this situation.
\end{abstract}

KEY WORDS: Malaria. Plasmodium Falciparum. Roll Back Malaria. Malaria Control. Sindh. Pakistan.

\section{INTRODUCTION}

Globally, about 300-500 million malaria cases occur every year. However, sub Saharan Africa is most affected region. Health systems failure, drug resistance, population movement, deteriorating sanitation, climatic changes and unplanned development activities are contributing to the spread of malaria. Estimated $1-2$ million deaths occur each year mainly in infants and children under 5 years of age due to cerebral malaria and in pregnant women caused by plasmodium falciparum. Malaria kills a child every 30 seconds often in combination with other diseases. Acute malarial disease may kill a child within 24 hours. In endemic countries, women are four times more likely to suffer malaria attacks during pregnancy resulting in low weight babies and stillbirths. Moreover, nearly $60 \%$ of miscarriages in hyperendemic areas are also due to malaria. $^{1}$

In Pakistan, half a million-malaria cases occur annually and Sindh and Balochistan are more affected provinces. Malaria is cause of estimated fifty thousand deaths each year mostly in infants, children and pregnant women. Hence, malaria is a major public health problem of this country, which threatens millions of people. ${ }^{2}$ This higher mortality is due to lack of awareness and application of malaria case management guidelines in high-risk severe and complicated falciparum malaria. ${ }^{3}$ Malaria endemic regions are some of the world's most impoverished areas where plasmodium falciparum is responsible mainly for deaths and plasmodium vivax for morbidity and number of malaria attacks. ${ }^{1}$ Hence, one reason for the below poverty indicators of Sindh and Balochistan especially in their 
coastal, remote and arid districts can be high annual parasite incidence in these areas. ${ }^{4}$ Annual parasite incidence and plasmodium falciparum ratio in Sindh are increasing as reported in year 2004. Many cerebral malaria epidemics have also been reported in post flood and rainy seasons from coastal districts of Sindh during year 2003. ${ }^{5}$ Roll Back Malaria is a new global initiative launched in 1998 by World Health Organization (WHO) along with other partners. It is also launched in Pakistan with the aim to control malaria related mortality and morbidity by year 2010. Integrated Management of Childhood Illnesses (IMCl) and Child Survival and Development Strategy recommend management of fever according to risk level of falciparum malaria. ${ }^{6}$ An updated malaria map for all districts of Pakistan in all seasons is urgently required to optimize malaria management in the country especially in children and pregnant women. Malaria control program in Sindh is actively doing blood smear examinations and reporting and collecting data of these cases. Main objectives of our study were to assess district wise and month wise malaria burden in Sindh province of Pakistan and to identify districts and months where malaria parasite incidence and / or risk of plasmodium falciparum ratio are high so that appropriate measures are taken to control this problem.

\section{METHODS}

Malaria Control Program (MCP) in Sindh province of Pakistan is working in all districts in government healthcare facilities. Malaria microscopists are specially trained to examine the smear and recognize the specie of parasite. These health workers also have medicines to treat uncomplicated malaria cases and refer complicated cases. They are also responsible for implementation of preventive strategies. They collect blood slides from malaria suspected cases door to door (active case detection) or malaria suspected patients come to them for blood smear examination (passive case detection). Health workers and microscopist's teams also collect blood slides in children under ten years of age from epidemiological areas (malariometric survey). Passive case detection contributes major share in slide collection. Monthly reports are then sent from each district to provincial malaria directorate at Hyderabad where these are compiled and analyzed in a central pool by epidemiologists to monitor surveillance activities. Malaria supervisors and senior microscopists monitor the work of health workers including the reliability of microscopy. All monthly data is computerized and tabulated according to district and months. Blood examination rate (BER: All slides $\times 100 / P o p u l a t i o n)$, slide positivity rate (SPR: Total positive slides $\times 100 /$ Total slides), Specie differentiation and falciparum ratio (FR\%: Total falciparum $x$ 100/Total positive) and Annual parasite incidence (API: Total positive cases $\times 1000 /$ Population) are then calculated. Plasmodium vivax constitutes the remaining burden of malaria when falciparum ratio is subtracted. For this descriptive study, surveillance data of malaria collected and analyzed by provincial malaria control program is presented. However, incomplete age wise data from some districts was excluded from the study.

\section{RESULTS}

During years 2004 and 2005, more than 2.82 million blood slides were observed in whole province by technicians of malaria control program in all districts. Average BER in the province in two years was 4 . Slide positivity rate was 2.36 for two years. Average annual parasite incidence was reported 0.94 from these limited government health facilities alone and estimated ratio was at least five times higher. Falciparum ratio was 33\% in year 2004 and 37.2\% in 2005 (Table I). In 2004, BER was more than 5 in eight districts i.e. Badin, Sanghar, Jacobabad, Shikarpur, Thatta, Dadu, Sukkur and Larkana out of total 16 districts. In three districts Thatta, Larkana and Khairpur, SPR was more than 2 and FR was $62 \%, 56 \%$ and $44 \%$ respectively. SPR was highest in Mithi (11.76) while BER was 3.93 and FR $20 \%$. Badin had BER of more than 8, FR 35\%, SPR 1.74 and API 1.29 (Table II). As the program coverage was less than $20 \%$ of population estimated, API is likely to be at least five times higher than the data shown. Minimum estimated annual parasite incidence was hence 25 in Mirpurkhas, 24 in Mithi, 16 in Khairpur, 12 in Nosheroferoz and about 7 in Thatta, Badin and Larkana each. District wise corresponding data for the year 2005 is presented in Table III. In 2005, annual parasite incidence was 3.05 in Khairpur, 2.72 in Mirpurkhas, 2.06 in Noshehro Feroz and more than 1 in Badin, Mithi, Shikarpur, Thatta and Sanghar. Falciparum ratio was very high in year 2005 . It was $62.61 \%$ in Thatta, $57.7 \%$ in Larkana, $45.6 \%$ in Sukkur, $44.6 \%$ in Khairpur, $44 \%$ in Mirpurkhas, $43 \%$ in Kashmore (Jacobabad) and $41.8 \%$ in Karachi. Month-wise data of years 2004 and 2005 is shown in Tables IV 
M. Akbar Nizamani, Nawaz A. Kalar and Imdad A. Khushk

and $\mathbf{V}$ respectively. This data reveals that slide positivity rate, parasite incidence and falciparum ratio started increasing in post rainy season of September, continued increasing until October and remained fairly high till January. Some districts like Thatta, Mithi, Mirpurkhas, Khairpur and Larkana become high-risk due to increased parasite incidence (mainly plasmodium vivax) and / or high FR in these months. Except Thatta and Larkana, in all other districts more than $50 \%$ of malaria was caused by plasmodium vivax, which is mainly responsible for high annual parasite incidence in Sindh. According to available data, districts with high, medium or low-risk for malaria are presented in Figure I. Limited data from some districts also show that in children less than 5 years FR was $39.9 \%$ as against the provincial average of $37.2 \%$ in year 2005 . SPR in children was highest (4.6) in Mirpukhas, followed by Larkana (2.48), Khairpur (1.39) and Badin (1.29). FR in children was highest in Badin (57.6), followed by Larkana (57), Thatta (47.5) and Karachi (46.2). It was more than 40 in Mirpurkhas and Nawabshah (Table VI).

TABLE I: COMPARISON OF TWO YEARS MALARIA DATA IN SINDH (2004-2005)

\begin{tabular}{|c|c|c|c|c|c|c|c|}
\hline Year & Slides seen & $\begin{array}{c}\text { Positive } \\
\text { slides }\end{array}$ & $\begin{array}{c}\text { Slide } \\
\text { Positivity } \\
\text { Rate (SPR) }\end{array}$ & $\begin{array}{c}\text { Blood } \\
\text { Examination } \\
\text { Rate (BER) }\end{array}$ & $\begin{array}{c}\text { Falciparum } \\
\text { Ratio (FR) }\end{array}$ & $\begin{array}{c}\text { Annual } \\
\text { Parasite } \\
\text { Incidence } \\
\text { at MCP } \\
\text { Facilities }\end{array}$ & $\begin{array}{c}\text { Annual parasite } \\
\text { incidence (API): } \\
\text { Provincial } \\
\text { Estimate }\end{array}$ \\
\hline 2004 & 1521648 & 40697 & 2.67 & 4.22 & 33 & 1.12 & 5.6 \\
\hline 2005 & 13113818 & 27845 & 2.12 & 3.64 & 37.2 & 0.77 & 3.85 \\
\hline
\end{tabular}

TABLE II: DISTRICT WISE MALARIA SURVEILLANCE FIGURES IN SINDH DURING 2004

\begin{tabular}{|l|c|c|c|c|c|c|}
\hline \multicolumn{1}{|c|}{ District } & Slides & Positive & PFR & BER & API & SPR \\
\hline Hyderabad & 124936 & 2784 & 28 & 3.96 & 0.80 & 2.28 \\
\hline Badin & 103463 & 1803 & 35 & 8.4 & 1.29 & 1.74 \\
\hline Khairpur & 109369 & 6675 & 44 & 0.05 & 3.22 & 6.10 \\
\hline Nawabshah & 71963 & 2041 & 28 & 0.05 & 1.65 & 2.83 \\
\hline Nosheroferoz & 84297 & 3043 & 37 & 0.06 & 2.38 & 3.60 \\
\hline MirpurKhas & 107690 & 5804 & 27 & 0.09 & 5.01 & 5.38 \\
\hline Mithi & 46450 & 5466 & 12 & 3.93 & 4.78 & 11.7 \\
\hline Sanghar & 142768 & 2063 & 20 & 7.65 & 1.11 & 1.44 \\
\hline Sukkur & 56813 & 658 & 33 & 4.8 & 0.56 & 1.15 \\
\hline Ghotki & 40385 & 727 & 26 & 3.19 & 0.58 & 1.8 \\
\hline Jacobabad & 116562 & 1144 & 27 & 6.64 & 0.64 & 0.98 \\
\hline Shikarpur & 68530 & 1313 & 26 & 6.11 & 1.12 & 1.91 \\
\hline Larkana & 121023 & 3139 & 56 & 4.69 & 1.14 & 2.59 \\
\hline Dadu & 117749 & 1301 & 22 & 5.49 & 0.59 & 1.10 \\
\hline Thatta & 86684 & 1807 & 62 & 6.24 & 1.32 & 2.08 \\
\hline Karachi & 122966 & 929 & 35 & 0.91 & 0.07 & 0.75 \\
\hline TOTAL & $\mathbf{1 5 2 1 6 4 8}$ & $\mathbf{4 0 6 9 7}$ & $\mathbf{3 3}$ & $\mathbf{4 . 2 2}$ & $\mathbf{1 . 1 2}$ & $\mathbf{2 . 1 2}$ \\
\hline
\end{tabular}


TABLE III: DISTRICT WISE SURVEILLANCE FIGURES OF YEAR 2005

\begin{tabular}{|l|c|c|c|c|c|c|}
\hline \multicolumn{1}{|c|}{ District } & Slides & Positive & PFR & BER & API & SPR \\
\hline Hyderabad & 116429 & 1253 & 22.1 & 3.57 & 0.38 & 1.07 \\
\hline Badin & 84116 & 1623 & 35.7 & 6.47 & 1.24 & 1.93 \\
\hline Khairpur & 106066 & 5555 & 44.6 & 5.84 & 3.05 & 5.23 \\
\hline Nawabshah & 58607 & 1111 & 22 & 4.96 & 0.94 & 1.89 \\
\hline Nosheroferoz & 75534 & 3429 & 38.7 & 6.31 & 2.06 & 4.54 \\
\hline MirpurKhas & 64729 & 2891 & 44 & 6.09 & 2.72 & 4.46 \\
\hline Mithi & 30674 & 1357 & 12.7 & 3.06 & 1.23 & 4.42 \\
\hline Sanghar & 135364 & 1919 & 24.6 & 7.92 & 1.12 & 1.41 \\
\hline Sukkur & 47900 & 526 & 45.6 & 4.44 & 0.48 & 1.09 \\
\hline Ghotki & 35507 & 632 & 35.1 & 3.01 & 0.53 & 1.78 \\
\hline Jacobabad & 83652 & 789 & 29 & 7.96 & 0.75 & 0.94 \\
\hline Shikarpur & 72628 & 1048 & 32.9 & 7.18 & 1.03 & 1.44 \\
\hline Larkana & 103716 & 1990 & 57.7 & 4.47 & 0.85 & 1.91 \\
\hline Dadu & 89858 & 1841 & 24 & 4.54 & 0.52 & 1.15 \\
\hline Thatta & 70561 & 1331 & 62.6 & 5.54 & 1.04 & 1.88 \\
\hline Umerkot & 16152 & 496 & 31 & 2 & 0.89 & 4.45 \\
\hline Kashmore & 16157 & 125 & 43.2 & 2.63 & 0.35 & 1.33 \\
\hline Karachi & 106169 & 416 & 41.8 & 0.87 & 0.03 & 0.39 \\
\hline TOTAL & $\mathbf{1 3 1 3 8 1 8}$ & $\mathbf{2 7 8 4 5}$ & $\mathbf{3 7 . 2}$ & $\mathbf{3 . 6 4}$ & $\mathbf{0 . 7 7}$ & $\mathbf{2 . 1 2}$ \\
\hline
\end{tabular}

TABLE IV: MONTH WISE SURVEILLANCE FIGUGERS IN YEAR 2004

\begin{tabular}{|l|c|c|c|c|c|c|}
\hline \multicolumn{1}{|c|}{ Month } & Slides & Positive & PFR & BER & PI & SPR \\
\hline January & 97973 & 2674 & 55 & 0.63 & 0.17 & 1.88 \\
\hline February & 117460 & 2576 & 35 & 0.74 & 0.16 & 1.45 \\
\hline March & 127550 & 2700 & 27 & 0.49 & 0.1 & 1.48 \\
\hline April & 124385 & 3523 & 29 & 0.48 & 0.13 & 1.71 \\
\hline May & 121723 & 4285 & 27 & 0.47 & 0.16 & 2.27 \\
\hline June & 123779 & 3253 & 17 & 0.48 & 0.12 & 1.98 \\
\hline July & 141087 & 3233 & 16 & 0.55 & 0.12 & 2.09 \\
\hline August & 142467 & 3793 & 21 & 0.55 & 0.14 & 2.28 \\
\hline September & 151017 & 4261 & 29 & 0.6 & 0.17 & 2.4 \\
\hline October & 126942 & 3730 & 38 & 0.84 & 0.24 & 3 \\
\hline November & 116716 & 3285 & 51.4 & 0.75 & 0.21 & 3 \\
\hline December & 130549 & 3384 & 54 & 0.36 & 0.09 & 2.49 \\
\hline Total & $\mathbf{1 5 2 1 6 4 8}$ & $\mathbf{4 0 6 9 7}$ & $\mathbf{3 3}$ & $\mathbf{4 . 2 2}$ & $\mathbf{1 . 1 2}$ & $\mathbf{2 . 1 2}$ \\
\hline
\end{tabular}


M. Akbar Nizamani, Nawaz A. Kalar and Imdad A. Khushk

TABLE V: MONTH WISE MALARIA SURVEILLANCE FIGURES IN 2005

\begin{tabular}{|l|c|c|c|c|c|c|}
\hline \multicolumn{1}{|c|}{ Month } & Slides & Positive & PFR & BER & PI & SPR \\
\hline January & 110055 & 2069 & 52 & 0.7 & 0.13 & 1.87 \\
\hline February & 106397 & 1542 & 38 & 0.68 & 0.09 & 1.44 \\
\hline March & 124091 & 1838 & 31 & 0.34 & 0.05 & 1.48 \\
\hline April & 116496 & 1998 & 29 & 0.32 & 0.05 & 1.71 \\
\hline May & 119093 & 2706 & 34 & 0.33 & 0.07 & 2.27 \\
\hline June & 107790 & 2137 & 29 & 0.29 & 0.05 & 1.98 \\
\hline July & 107652 & 2250 & 21.5 & 0.29 & 0.06 & 2.09 \\
\hline August & 104331 & 2387 & 24 & 0.28 & 0.06 & 2.28 \\
\hline September & 104776 & 2523 & 34 & 0.29 & 0.07 & 2.4 \\
\hline October & 106687 & 3044 & 37 & 0.27 & 0.08 & 2.85 \\
\hline November & 95822 & 2625 & 52 & 0.49 & 0.07 & 2.73 \\
\hline December & 110628 & 2726 & 54 & 0.29 & 0.07 & 2.46 \\
\hline Total & $\mathbf{1 3 1 3 8 1 8}$ & $\mathbf{2 7 8 4 5}$ & $\mathbf{3 7 . 2}$ & $\mathbf{3 . 6 4}$ & $\mathbf{0 . 7 7}$ & $\mathbf{2 . 1 2}$ \\
\hline
\end{tabular}

FIGURE I: MAP OF SINDH SHOWING RISK OF MALARIA IN VARIOUS DISTRICTS (2004-05)

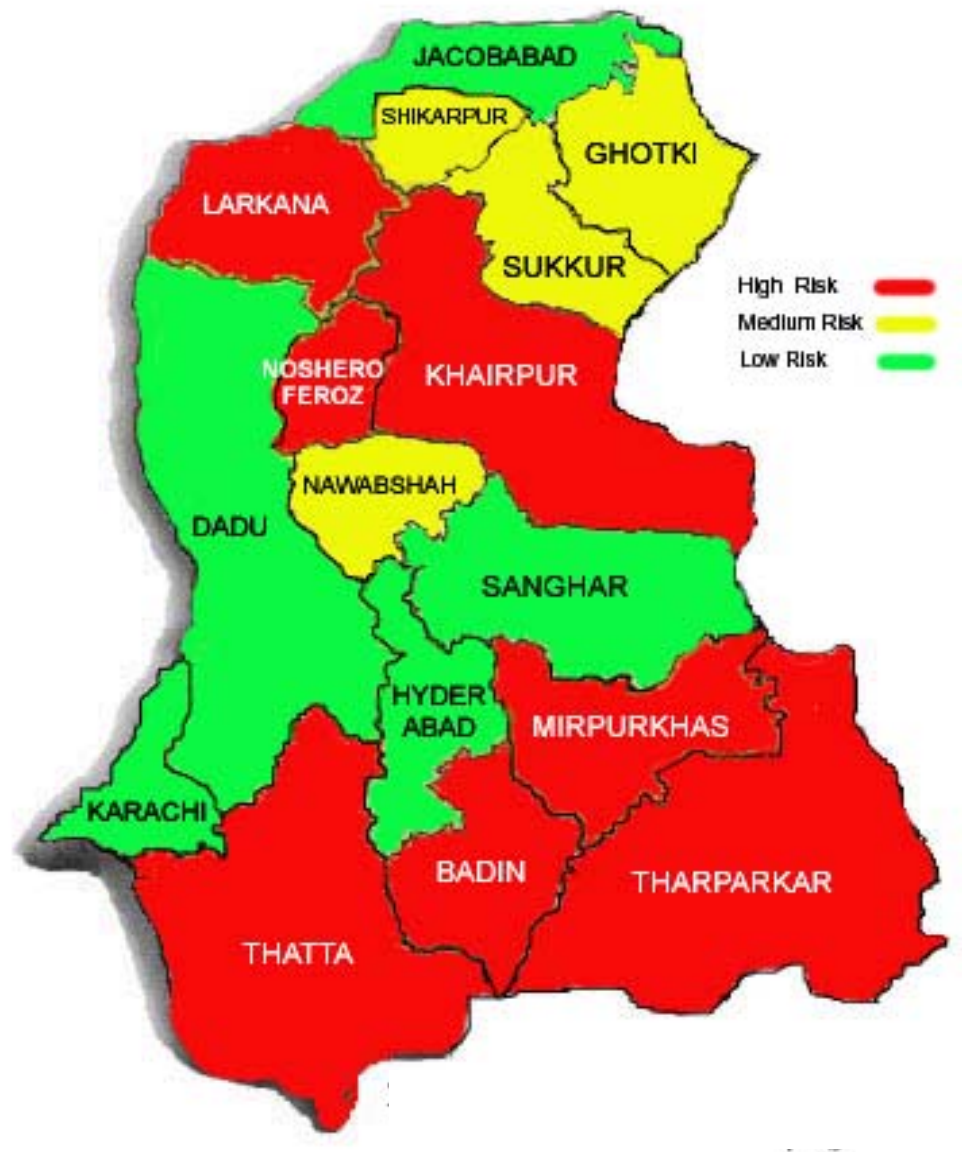


TABLE VI:

DISTRICT WISE FIGURES OF POSITIVE CASES IN CHILDREN UNDER 5 YEARS OF AGE IN SINDH (YEAR 2005)

\begin{tabular}{|l|c|c|c|c|}
\hline \multicolumn{1}{|c|}{ DISTRICT } & SLIDES SEEN & SLIDES POSITIVE & \% OF POSITIVE SLIDES & \% OF P.FALCIPARUM \\
\hline Mirpurkhas & 26384 & 1232 & 4.6 & 42.5 \\
\hline Larkana & 26908 & 668 & 2.48 & 57 \\
\hline Nawabshah & 17856 & 249 & 1.39 & 40.9 \\
\hline Badin & 22280 & 288 & 1.29 & 57.6 \\
\hline Sanghar & 33150 & 410 & 1.2 & 20.2 \\
\hline Shikarpur & 21752 & 235 & 1.08 & 20 \\
\hline Jacobabad & 18070 & 177 & 0.97 & 20.6 \\
\hline Karachi & 40655 & 93 & 0.89 & 46.2 \\
\hline Dadu & 20812 & 180 & 0.86 & 22.2 \\
\hline Hyderabad & 36690 & 330 & 0.8 & 15.5 \\
\hline Thatta & 23178 & 208 & 0.89 & 47.5 \\
\hline Others & 7700 & 159 & 2.06 & 57.8 \\
\hline Total & $\mathbf{2 9 5 4 3 5}$ & $\mathbf{4 2 2 7}$ & $\mathbf{1 . 4}$ & $\mathbf{3 9 . 4}$ \\
\hline
\end{tabular}

\section{DISCUSSION}

In years 2004 and 2005, more than 2.82 million blood slides were seen in Sindh province by technicians of Malaria Control Program in all districts. Average BER for the two years was 4 which is little less than the optimum required level of 5 . SPR was 2.36 for two years which is more than minimum malaria control level i.e. 2. API and FR are major indicators of malaria morbidity and mortality globally. Average API is 0.94 from limited health facilities alone. As not more than $20 \%$ population is availing the government health facilities and many facilities have no malaria microscopists, minimum estimates are that this incidence is at least 5-10 times higher i.e 4.65 to 9.3. This figure is very high than the minimum malaria control level of $<0.5$. As Karachi with about $25 \%$ of the provincial population has very low API the same in the interior districts of Sindh will even be higher than the estimates. FR on average was 33\%, which is less than high-risk level of $40 \%$. But this ratio was more than $40 \%$ in many districts. Parasite incidence and FR start increasing in September, peak in October and remain fairly high till January. Both malaria morbidity and parasite density as reported from Punjab by Prybylski, et al are lower than these figures. ${ }^{7}$ In 2004, BER was optimum or reasonable in eight districts i.e. Badin, Sanghar, Jacobabad, Shikarpur, Thatta, Dadu, Sukkur and Larkana. Situation was alarming in two districts;
Thatta and Larkana where SPR was more than 2 and FR $62 \%$ and $56 \%$ respectively. SPR and FR (44\%) were higher in Khairpur as well but BER was very low, so result may represent a fixed locality. SPR was observed highest in Mithi (11.76), which is a desert district, BER was 3.93, which is less than optimum, but fortunately FR was low (20\%). Badin with a good BER represented average provincial scenario well with $35 \%$ FR, SPR 1.74 and API 1.29 (i.e. 6.45 minimum). Estimated API was at least 25 in Mirpurkhas, 24 in Mithi, 16 in Khairpur, 12 in Noshehroferoz and about 7 in Thatta, Badin and Larkana respectively. Low API reported in 2005 may be due to less number of slides seen in that year but FR was very high in the same year, which is alarming. It was $62.61 \%$ in Thatta, $57.7 \%$ in Larkana, $45.6 \%$ in Sukkur, $44.6 \%$ in Khairpur, 44\% in Mirpurkhas, $43 \%$ in Kashmore and $41.8 \%$ in Karachi. Three districts with highest average API $(>3)$ for two years included Mirpurkhas, Khairpur and Mithi. Thatta stood out as the district with more than $62 \%$ FR in both years. Other districts with high average FR were Larkana (56.8) and Khairpur (44.3). Mirpurkhas and Badin had average FR of more than $35 \%$. High FR is mainly responsible for malaria related deaths in children and pregnant women. Hashim MJ has also reported high incidence of malaria in rural Sindh and Balochistan. He has reported $3.6 \%$ of positive blood smears for malaria and has calculated FR 
$49 \%$ from all government health facilities of the country. He has also reported increased FR of more than $80 \%$ in Coastal Balochistan, Sibi, Nawabshah and Lodhran. ${ }^{8}$ Our data supports high FR in Coastal Thatta but FR was lower in Nawabshah. Data regarding children is limited. Districts Mirpurkhas, Larkana, Thatta and Badin stand out as having more cases of malaria with higher FR. Hashim MJ has reported that in rural Sindh median age for children presenting with fever or history of fever is 2 years, $6 \%$ have blood smear positive for malarial parasite, $65 \%$ of them with falciparum. Hozhabri, et al have also given similar figures from areas near Manchar Lake in district Dadu, Sindh. On the basis of this data, it can be concluded that Thatta, Badin, Mirpurkhas, Mithi, Larkana, Khairpur and Nosheroferoz are potential high-risk districts in Sindh in months from September to January. Malaria case management is poorly done in Pakistan and clinical diagnostic guidelines are also not followed. Malaria microscopy from pathology laboratories in general is very poor and drug use is irrational. Plasmodium vivax is still sensitive to first-line anti-malarial drugs like Chloroquine but plasmodium falciparum drug resistance has become a global problem. Resistance against Chloroquine by plasmodium falciparum has been a problem since many years ${ }^{9}$ and is increasing $^{10}$ against other drugs as well. There are also apprehensions of resistance to even new drugs like Artemether. ${ }^{11}$ Therefore, WHO is working on Artimether combination compounds to overcome the problem of drug resistance. ${ }^{12}$ Side effects of drugs are another problem mainly due to irrational use of anti-malarial drugs like Fancidar in every fever causing bone marrow suppression. Majority of general practitioners are using injectable Chloroquine instead of Quinine which is the drug of first choice in complicated malaria. Hence, cerebral malaria due to plasmodium falciparum is resulting in death of large number of infants and pregnant women in the country especially rural Sindh and Balochistan. ${ }^{13}$ Untrained health workers including doctors are using various forms of Sulfadoxine-Pyrimethamine combinations (Fancidar) in high and multiple doses in every fever without malaria microscopy or even in vivax malaria where Fancidar is not effective which leads to many cases of bone marrow suppression or blood dyscrasias. ${ }^{14} \mathrm{IMCl}$ is a new initiative to train doctors, health workers and community to correctly assess, classify and manage life threatening and common problems including fever. $\mathrm{IMCl}$ protocol's correct implementation needs a map of area according to high or low-risk of malaria as treatment guidelines are different in each category. ${ }^{6}$ This study therefore first time identifies potential highrisk districts in peak malaria season in Sindh to implement IMCI protocols correctly. Pakistan is exposed to malaria as a major public health problem, which threatens millions of people, but situation is worse in Sindh and Balochistan. High API indicates increased morbidity due to plasmodium vivax, which leads to financial and school losses. Malaria and gross national product are inversely related and it presents a great human and economic challenge to the world as a cause of poverty, ill health and death. Now, it is considered that malaria and poverty produce each other, especially by decreasing agricultural products by $60 \%$ and affecting the poor rural farmer families of the affected region. Workers affected by malaria can be incapacitated for 5-20 days, family suffer an average of over one quarter of their income on malaria treatment and prevention. A WHO surveillance report has confirmed that peak season of malaria in Sindh coincides with agricultural activities hence affecting the output. It reports that API in Pakistan was 0.8 and FR was highest in Sindh i.e. $46 \%$ in $2003 .{ }^{15}$ Containment of the spread of disease is the only feasible option so far. Malaria control program in the country and provinces is actively involved with WHO sponsored Roll Back Malaria Initiative to improve the malaria situation. Specific objectives at present are to increase the availability of correct assessment and treatment at health facilities and in communities, and to improve detection and control of malaria outbreaks. As both API and FR are not uniform within the country so budget allocation and program implementation under Roll Back Malaria Initiative shall be decentralized according to the malaria situation in provinces and districts. An updated district wise malaria map of country for $\mathrm{IMCl}$ protocol implementation is also urgently needed.

\section{ACKNOWLEDGEMENTS}

Authors are thankful to all malaria technicians, Dr. Khalid Talpur, Senior Evaluator Malaria Control Program, Sindh; Mr. Ismaeel Brohi, Mr. Ihsan Danish Nizamani and Dr. Asif Sherani for their technical help.

\section{REFERENCES}

1. Roll Back Malaria. WHO. Malaria - a global crisis. Fact Sheet no. 1211- Geneva Switzerland, 2002.

2. Roll Back Malaria. WHO Eastern Mediterranean Region. Cairo, Egypt. 2002; Pp. 1-14.

3. National HMIS Cell. Situation of clinical malaria (fever) in Pakistan. National HMIS data 19982000 , Islamabad. Ministry of Health, Govt. of Pakistan, 2001.

4. National Treatment Guidelines for Malaria. Directorate of Malaria Control. Ministry of Health Pakistan and WHO.2003.

5. Hozhabri S, Akhtar S, Rahbar MH, Luby SP. Prevalence of plasmodium positivity among the 
children treated for malaria, Jhangara, Sindh. J Pak Med Assoc. 2000; 5: 401-5.

6. Model Chapter for Textbooks - Integrated Management of Childhood Illnesses. Geneva: World Health Organization - Child and Adolescent Health; 2001.

7. Prybylski D, Khaliq A, Fox E, Sarwari AR, Strickland GT. Parasite density and malaria morbidity in the Pakistani Punjab. Am J Trop Med Hyg. 1999;61:791-801.

8. Hashim MJ . Primary Care in Pakistan. 2003; Pp. 1-10.

9. Nizamani MA and Memon MHA. Cerebral malaria in children: a study of 50 cases. Pak Pediatr J. 1995;19:1-17.

10. Rab MA, Freeman TW, Durrani N, de Poerck D, Rowland MW. Resistance of Plasmodium falciparum malaria to chloroquine is widespread in eastern Afghanistan. Ann Trop Med Parasitol. 2001;95:41-6.
11. Jambou R, Legrand E, Niang $M$, Khim N, Lim P, Volney $\mathrm{B}$, et al. Resistance of Plasmodium falciparum field isolates to in-vitro artemether and point mutations of the SERCA-type PfATPase6. Lancet. 2005;366:1960-3.

12. Adjuik M, Babiker A, Garner P, Olliaro P, Taylor W, White N; International Artemisinin Study Group. Artesunate combinations for treatment of malaria:meta-analysis. Lancet. 2004; 363: 9-17.

13. Durrani AB, Durrani IU, Abbas N, Jabeen $M$. Epidemiology of cerebral malaria and its mortality. J Pak Med Assoc. 1997; 47;213-5.

14. Hafiz R, Munir MA. A time for serious consideration towards the irrational use of antimalarial drugs in Pakistan. Pak J Med Res. 1995;34:134-5.

15. WHO Report on malaria surveillance. Malaria Control Program Pakistan. Available at: www.emro.who.int/rbm/Pak.htm. Accessed and cited in June 2006.

AUTHOR AFFILIATION:

Prof. M. Akbar Nizamani (Corresponding Author)

Department of Paediatrics

Liaquat University of Medical and Health Sciences

(LUMHS) Jamshoro - Sindh.

E-mail:adnizamani@hotmail.com

Dr. Nawaz A. Kalar

Director, Provincial Malaria Control Program

Hyderabad - Sindh.

Dr. Imdad A. Khushk

Senior Research Officer

Medical Research Centre

LUMHS Jamshoro - Sindh.

E-mail: imdadkhushk@yahoo.com 